\title{
ABC of Face Validity for Questionnaire
}

\author{
Sharad Desai ${ }^{1}$, Nilesh Patel ${ }^{2 *}$ \\ 1 Ph.D Research Scholar, Ganpat University, Ganpat Vidyanagar-384012, Mehsana, Gujarat, India. \\ 2 Associate Professor \& Head, Department of pharmacology, Shree S. K. Patel College of Pharmaceutical Education and Research, \\ Ganpat University, Ganpat Vidyanagar-384012, Mehsana, Gujarat, India. \\ *Corresponding author's E-mail: nileshcology127@gmail.com
}

Received: 10-08-2020; Revised: 18-10-2020; Accepted: 25-10-2020; Published on: 15-11-2020.

\begin{abstract}
Validity of questionnaire means to verify what we are measuring is intended to measure? Which is usually done before administration of final questionnaire to the sample for the construct. The main four types of validity methods are: face, content, criterion-related and construct validity. So many times, the questionnaire studies are done without any validity check due to absence of knowledge for any kind of validity, time constrain, research scheme complexities, exceptional questionnaire and limitation of resources. One of four, face validity is simplest and easiest validity process but in absence of proper guideline, researches are avoiding to perform it and to take the subjective opinion about appearance and content of the questionnaire which provides substantial evidence for the validity of construct, which must be checked for any questionnaire before beginning of work. Hence, this paper describes systemic process for simplest face validity supported by literature and best practice with its limitations and recommendations. Limitation of use of Cohen's Kappa Index and Fleiss' kappa for evaluation of face validity of tool is explained. Described method can help to questionnaire research works in various fields like social, physiological, medicinal etc.
\end{abstract}

Keywords: Questionnaire, Face validity, Content validity, Questionnaire validation

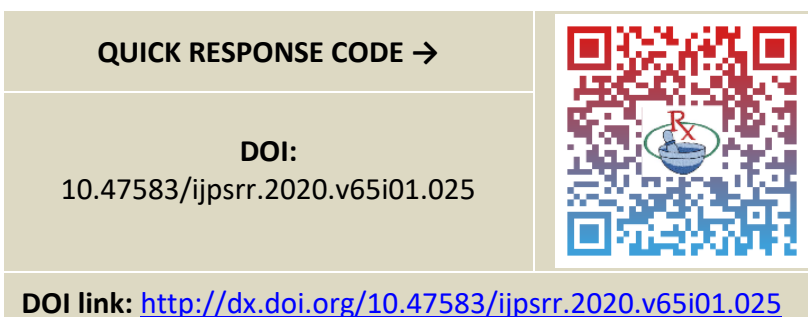

\section{INTRODUCTION}

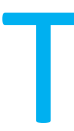

he four validity methods, viz. face, content, criterionrelated and construct are respectively defined as (I) checking of tool for its validity on the face of it, (II) representativeness of content for construct, (III) to evaluate how one tool foresee results of another one, (IV) it is degree to which construct measures what it claims. ${ }^{1,2}$ The main aim of questionnaire validity is to check that developed tool is valid for its content, structure, proper responses and expected result. Which can be achieved with help of said one or more applicable validity methods. Many literature are available for explanation of validity methods/process so it is not explained here in detail or brief. But, in many case questionnaire research is done without any validity test due to absence of knowledge for any kind of validity tests, time constrain, research scheme complexities, exceptional questionnaire and limitation of resources. But, it is always important that questionnaire must be validated. So when no validity is going to be performed due to said any one or more reasons, it is always advisable to go with at least face validity. With help of subjective face validity, questionnaire is evaluated for clarity, unambiguity, reasonability and relevancy. The clarity and unambiguity of an assessment questionnaire refer that the tool is not baffling for understanding and reading but also have adequate instruction to be followed. While, relevancy and reasonability mean appropriate questions are included for construct with appropriate difficulty level for sample.

Next section describes best method to perform the questionnaire's face validity with help of raters.

\section{Procedure for face validity}

Below five stages for face validity are particularized one by one:

\section{Preparing face validity form.}

2. Selection of expert panel.

3. Distribution and receipt of face validity form.

4. Review of received form and response compilation.

\section{5. \% calculation.}

\section{Stage 1. Preparing face validity form}

Preparation of validity form involves drafting of cover letter and response sheet. Cover letter helps panelist to understand their responsibility for assignment and expectation of author. Cover letter should include name \& address of author, introduction, project title, project purpose, instruction to be followed. Illustration of cover letter is given in Table 1. While, the response sheet should include rate criteria, its rating scale, remarks, rater's name, rater's qualification, rater's years of experience, rater's profession and date of response. Illustration of response sheet is stated in Table 2. 
Table 1: Illustration of Cover Letter

Name: [Name of rater]

Address: [Address of rater]

Respected Sir/Madam,

Subject: Request for input for face validity of Questionnaire.

I am [Name of rater] having a qualification of [Name of degree]. Right now I am pursuing a [Detail of ongoing work/study] at [Name of organization]. I am going to collect the data through a self-administered Questionnaire in my project. As a part of validation of said Questionnaire, I have to do the Face validity (i.e. to check the extent of appropriateness of questionnaire to claim the validity and ability to measure the purpose) of Questionnaire. So I sincerely request you to go through the below information and instructions and share the response in the response sheet on the next page. Feel free to contact at above address for any concern.

Project title: [Name of project]

Project purpose: [Purpose of project]

Instruction to be followed

- Refer the questionnaire in detail from page number $x \mathrm{x}$ to $\mathrm{xx}$. Also review the hard copy of questionnaire.

- Mention 'Yes'/'No' for the questions considering the content of Questionnaire.

- Where: 'Yes' means you are agree with criteria for objective of construct and 'No' means not in agreement.

- After answering, mention your remark (if any), name, qualification, total experience, profession and date at end of response sheet.

- In remark section, you can give the recommendation and suggestion to improve the structure of the question(s) and questionnaire as whole.

- $\quad$ Save the file and send it back to me.

- If nothing to write then state 'Not Applicable' as all fields are mandatory.

Table 2: Illustration of Response Sheet

\begin{tabular}{|c|c|c|c|}
\hline \multirow{2}{*}{$\begin{array}{l}\text { Sr. No. } \\
\text { Que.: } 01\end{array}$} & \multirow{2}{*}{$\begin{array}{c}\text { Criteria to rate } \\
\text { Appropriateness of grammar. }\end{array}$} & \multicolumn{2}{|c|}{ Answer } \\
\hline & & [ ] Yes & [ ] No \\
\hline Que.: 02 & The clarity and unambiguity of items. & [ ] Yes & [] No \\
\hline Que.: 03 & The correct spelling of words. & [ ] Yes & [ ] No \\
\hline Que.: 04 & The correct structuring of the sentences. & [ ] Yes & [ ] No \\
\hline Que.: 05 & Appropriateness of font size and space. & [ ] Yes & [ ] No \\
\hline Que.: 06 & Legible printout. & [ ] Yes & [ ] No \\
\hline Que.: 07 & Adequacy of instruction on the instrument. & [ ] Yes & [ ] No \\
\hline Que.: 08 & The structure of the instrument in terms of construction and well- thought out format. & [ ] Yes & [ ] No \\
\hline Que.: 09 & Appropriateness of difficulty level of the instrument for the participants. & [] Yes & [] No \\
\hline Que.: 10 & Reasonableness of items in relation to the supposed purpose of the instrument. & [ ] Yes & [ ] No \\
\hline \multicolumn{4}{|c|}{ Remark(s): } \\
\hline \multicolumn{4}{|c|}{ Filled by: } \\
\hline \multicolumn{4}{|c|}{ Qualification: } \\
\hline \multicolumn{4}{|c|}{ Total experience (Yrs.): } \\
\hline \multicolumn{4}{|c|}{ Profession: } \\
\hline & ate: & & \\
\hline
\end{tabular}




\section{Stage 2. Selection of expert panel}

There is not any guideline to select the panelist of face validity like content validity. $\frac{3}{-}$ But, expert with experience in topic/subject/work will be selected to evaluate it. More experts will be selected to get more opinion but, feasibility to handle the logistic should be considered. Based on experience, author suggests 10-12 experts can give enough and good recommendations.

Table 3 will help to report details of experts. To mention the names of experts in report is subjective and depends on permission of expert and guideline of report accepting authority.

Table 3: Details of Experts

\begin{tabular}{|c|c|c|c|c|}
\hline Name & Qualification & Total Experience (Years) & Profession & Remark(s) \\
\hline$X 1$ & XXXX & $X X X X$ & $X X X X$ & $X X X X$ \\
\hline- & $X X X X$ & $X X X X$ & $X X X X$ & $X X X X$ \\
\hline- & $X X X X$ & $X X X X$ & $X X X X$ & $X X X X$ \\
\hline$X 10$ & $X X X X$ & $X X X X$ & $X X X X$ & $X X X X$ \\
\hline
\end{tabular}

\section{Stage 3. Distribution and receipt of face validity form}

Response of validation form will be taken by either faceto-face (meeting or interview) or non-face-to-face (e-mail or snail-mail) but, both have their own merits and demerits which are discussed at the end of this stage. Even all details is stated in cover letter, at the time of requesting, it is always suggested to brief the process with request to give qualitative input to add, delete and/or modify any particular question as this will help to improve the questionnaire for clarity.

Normally, ten days are enough to revert. In case of no response, gentle follow up will be done. Face-to-face method is costlier and time consuming but has good response rate. While response rate is poor for Non-faceto-face method, which is cheaper and convenient.

\section{Stage 4. Review of received form and response compilation}

After receipt of form, it will be checked for completeness but can be send back to seek the missing information, if any. After having all completed forms, responses will be compiled in result table as stated in Table 4 with all received verbal or written remarks.

Table 4: Response Compilation

\begin{tabular}{|c|c|c|c|c|c|c|c|c|c|c|c|c|}
\hline \multirow{2}{*}{ Experts' Name } & \multicolumn{10}{|c|}{ Experts' Answer } & \multirow{2}{*}{$\begin{array}{l}\text { Experts' } \\
\text { Remarks }\end{array}$} & \multirow{2}{*}{$\begin{array}{l}\text { Action } \\
\text { taken for } \\
\text { remark }\end{array}$} \\
\hline & Q1 & Q2 & Q3 & Q4 & Q5 & Q6 & Q7 & Q8 & Q9 & Q10 & & \\
\hline $\mathrm{C} 1$ & $\mathrm{Y} / \mathrm{N}$ & $\mathrm{Y} / \mathrm{N}$ & $\mathrm{Y} / \mathrm{N}$ & $\mathrm{Y} / \mathrm{N}$ & $\mathrm{Y} / \mathrm{N}$ & $\mathrm{Y} / \mathrm{N}$ & $\mathrm{Y} / \mathrm{N}$ & $\mathrm{Y} / \mathrm{N}$ & $\mathrm{Y} / \mathrm{N}$ & $\mathrm{Y} / \mathrm{N}$ & $\mathrm{zz}$ & - \\
\hline C2 & $\mathrm{Y} / \mathrm{N}$ & $\mathrm{Y} / \mathrm{N}$ & $\mathrm{Y} / \mathrm{N}$ & $\mathrm{Y} / \mathrm{N}$ & $\mathrm{Y} / \mathrm{N}$ & $\mathrm{Y} / \mathrm{N}$ & $\mathrm{Y} / \mathrm{N}$ & $\mathrm{Y} / \mathrm{N}$ & $\mathrm{Y} / \mathrm{N}$ & $\mathrm{Y} / \mathrm{N}$ & $\mathrm{zz}$ & - \\
\hline C3 & $\mathrm{Y} / \mathrm{N}$ & $\mathrm{Y} / \mathrm{N}$ & $\mathrm{Y} / \mathrm{N}$ & $\mathrm{Y} / \mathrm{N}$ & $\mathrm{Y} / \mathrm{N}$ & $\mathrm{Y} / \mathrm{N}$ & $\mathrm{Y} / \mathrm{N}$ & $\mathrm{Y} / \mathrm{N}$ & $\mathrm{Y} / \mathrm{N}$ & $\mathrm{Y} / \mathrm{N}$ & $\mathrm{zz}$ & - \\
\hline C4 & $\mathrm{Y} / \mathrm{N}$ & $\mathrm{Y} / \mathrm{N}$ & $\mathrm{Y} / \mathrm{N}$ & $\mathrm{Y} / \mathrm{N}$ & $\mathrm{Y} / \mathrm{N}$ & $\mathrm{Y} / \mathrm{N}$ & $\mathrm{Y} / \mathrm{N}$ & $\mathrm{Y} / \mathrm{N}$ & $\mathrm{Y} / \mathrm{N}$ & $\mathrm{Y} / \mathrm{N}$ & $\mathrm{zz}$ & - \\
\hline C5 & $\mathrm{Y} / \mathrm{N}$ & $\mathrm{Y} / \mathrm{N}$ & $\mathrm{Y} / \mathrm{N}$ & $\mathrm{Y} / \mathrm{N}$ & $\mathrm{Y} / \mathrm{N}$ & $\mathrm{Y} / \mathrm{N}$ & $\mathrm{Y} / \mathrm{N}$ & $\mathrm{Y} / \mathrm{N}$ & $\mathrm{Y} / \mathrm{N}$ & $\mathrm{Y} / \mathrm{N}$ & $\mathrm{zz}$ & - \\
\hline C6 & $\mathrm{Y} / \mathrm{N}$ & $\mathrm{Y} / \mathrm{N}$ & $\mathrm{Y} / \mathrm{N}$ & $\mathrm{Y} / \mathrm{N}$ & $\mathrm{Y} / \mathrm{N}$ & $\mathrm{Y} / \mathrm{N}$ & $\mathrm{Y} / \mathrm{N}$ & $\mathrm{Y} / \mathrm{N}$ & $\mathrm{Y} / \mathrm{N}$ & $\mathrm{Y} / \mathrm{N}$ & $\mathrm{zz}$ & - \\
\hline C7 & $\mathrm{Y} / \mathrm{N}$ & $\mathrm{Y} / \mathrm{N}$ & $\mathrm{Y} / \mathrm{N}$ & $\mathrm{Y} / \mathrm{N}$ & $\mathrm{Y} / \mathrm{N}$ & $\mathrm{Y} / \mathrm{N}$ & $\mathrm{Y} / \mathrm{N}$ & $\mathrm{Y} / \mathrm{N}$ & $\mathrm{Y} / \mathrm{N}$ & $\mathrm{Y} / \mathrm{N}$ & $\mathrm{zz}$ & - \\
\hline C8 & $\mathrm{Y} / \mathrm{N}$ & $\mathrm{Y} / \mathrm{N}$ & $\mathrm{Y} / \mathrm{N}$ & $\mathrm{Y} / \mathrm{N}$ & $\mathrm{Y} / \mathrm{N}$ & $\mathrm{Y} / \mathrm{N}$ & $\mathrm{Y} / \mathrm{N}$ & $\mathrm{Y} / \mathrm{N}$ & $\mathrm{Y} / \mathrm{N}$ & $\mathrm{Y} / \mathrm{N}$ & $z z$ & - \\
\hline C9 & $\mathrm{Y} / \mathrm{N}$ & $\mathrm{Y} / \mathrm{N}$ & $\mathrm{Y} / \mathrm{N}$ & $\mathrm{Y} / \mathrm{N}$ & $\mathrm{Y} / \mathrm{N}$ & $\mathrm{Y} / \mathrm{N}$ & $\mathrm{Y} / \mathrm{N}$ & $\mathrm{Y} / \mathrm{N}$ & $\mathrm{Y} / \mathrm{N}$ & $\mathrm{Y} / \mathrm{N}$ & $\mathrm{zz}$ & - \\
\hline C10 & $\mathrm{Y} / \mathrm{N}$ & $\mathrm{Y} / \mathrm{N}$ & $\mathrm{Y} / \mathrm{N}$ & $\mathrm{Y} / \mathrm{N}$ & $\mathrm{Y} / \mathrm{N}$ & $\mathrm{Y} / \mathrm{N}$ & $\mathrm{Y} / \mathrm{N}$ & $\mathrm{Y} / \mathrm{N}$ & $\mathrm{Y} / \mathrm{N}$ & $\mathrm{Y} / \mathrm{N}$ & $z z$ & - \\
\hline C11 & $\mathrm{Y} / \mathrm{N}$ & $\mathrm{Y} / \mathrm{N}$ & $\mathrm{Y} / \mathrm{N}$ & $\mathrm{Y} / \mathrm{N}$ & $\mathrm{Y} / \mathrm{N}$ & $\mathrm{Y} / \mathrm{N}$ & $\mathrm{Y} / \mathrm{N}$ & $\mathrm{Y} / \mathrm{N}$ & $\mathrm{Y} / \mathrm{N}$ & $\mathrm{Y} / \mathrm{N}$ & $\mathrm{zz}$ & - \\
\hline $\begin{array}{c}\% \text { of per Question } \\
\text { Agreement }\end{array}$ & $\mathbf{X X} \%$ & XX \% & XX \% & $X X \%$ & XX \% & $x X \%$ & XX \% & XX \% & $\mathbf{X X} \%$ & XX \% & - & - \\
\hline \multicolumn{6}{|c|}{$\%$ of overall agreement } & \multicolumn{7}{|c|}{$x X \%$} \\
\hline
\end{tabular}

\section{Stage 5. \% calculation:}

As said by Lynn Mary R. $\stackrel{4}{ }$ and Zamanzadeh et al. $\sqrt{5}$, Face validity is unstandardized approach and unquantified in nature. Hence, author suggests that the best way to quantify the response is to calculate the $\%$ of agreement as stated in Table 4. Said \% for question and overall agreement will be calculated by equation No.: 1 and 2 respectively. 


\section{Equation No.: 1}

$\frac{\text { No. of agreed raters per question }}{\text { Total number of ratersper question }} \times 100 \%$

Equation No.: 2 $\frac{\text { Sum of } \% \text { of all queastions }}{\text { Total number of questions }}$

Based on experience and extensive literature search, below Table 5 is proposed to be followed to retain, redefine or restructure the area covered under per question and entire tool.

Table 5: Interpretation and Acceptability of \% of Agreement

\begin{tabular}{|c|c|c|}
\hline$\%$ of agreement & Strength of Agreement per question or overall & Action for each Question / entire tool \\
\hline$<80$ & Poor & Restructure \\
\hline $80-90$ & Substantial & Revise \\
\hline $90-100$ & Full & Retain \\
\hline
\end{tabular}

Based on result of Table 5, the questionnaire will be modified along with considering the remark(s) from each rater. Action taken for remark for each rated will be reported as per last column of Table 4. Once questionnaire is revised, it should be send back to all rater for their reference.

\section{Important notes to be considered}

In research paper, $\underline{6}$ face validity is evaluated by Cohen's Kappa Index (CKI) but, it can be applied only when below bulleted all five criteria meet. $\underline{\underline{ }}$

- Only two raters are required.

- Two rates are independent.

- Same two raters judge all the questions.

- Each question has same rating scale.

- Both raters assess the same observations.

Due to first point, CKI cannot be applied for suggested face validity method as author suggests to take the opinion of ten to twelve raters (to have enough and good recommendations) when only face validity is done due to limitations mentioned earlier. With respect to fifth point, opinion of two raters cannot helps to evaluate $C K I$ for questions in Table 2 as observation criteria is not same for all questions.

Fleiss' kappa is another method to check the agreement for two or more raters, if following all criteria meet. $\underline{8}$

- Two or more raters are required.

- Category for each question should be either nominal variable or an ordinal variable.

- Response for category should be exclusive (i.e. only one).

- Number of category / observation criteria to select for response should be same for all raters.

- Judgement of each rater should be independent

- Target being rated are randomly selected from population.
At first it feels, Fleiss' kappa is useful due to provision to calculate the opinion of two or more raters, which is limitation of $C K I$. But, as per last bullet point, each question should be rated by different group (two or more) of raters (Example can be referred at https://statistics.laerd.com) so for ten questions at least twenty raters are needed which increases the logistic. Even, opinion of twenty raters cannot helps to evaluate Fleiss' kappa for questions in Table 2 as observation criteria is not same for all questions, which should be same as per forth point.

So author suggests, \% approach is best rather than inappropriate CKI and Fleiss' kappa methods to check rater agreement for suggested method of face validity.

\section{DISCUSSION}

Face validity is non-statistical assessment in nature i.e. no quantitative methods are used for face validity calculation. However, when questionnaire validation is not feasible/possible by other quantitative validity methods due to time constrain, type of research, type of questionnaire and limitation of resources; face validity is important method to confirm the overall validity of prepared research tool. Therefore, detail, and experience and evidence-based process mentioned in this paper can help to get \% of agreement of raters to complete face validity. But, with this paper author also recommends that face validity is unquantified method so it should be used only if other methods are not suitable or it is followed by suitable quantitative validity methods. Any other suitable questions are required then those should assess during face validity. Also, other methods, viz. CKI and Fleiss' kappa to perform inter-rater agreement for face validity is not correct.

Acknowledgement: The authors' sincere thanks to Ganpat University and its S. K. Patel College of Pharmaceutical Education and Research, Ganpat Vidyanagar-384012, India for providing the necessary facilities to carry out this work. The authors are grateful to Mrs. Taruna Desai and Ms. Ramila Chaudhari for proof reading of the article.

- The two or more raters are non-unique. 


\section{REFERENCES}

1. Oladimeji Akeem Bolarinwa, Principles and Methods of Validity and Reliability Testing of Questionnaires Used in Social and Health Science Researches, Nigerian Postgraduate Medical Journal, 22(4), 2015, 195-201.

2. Oluwatayo, James Ayodele, Validity and Reliability Issues in Educational Research, Journal of Educational and Social Research, 2(2), 2012 391-400.

3. Lawshe C. H., A Quantitative Approach to Content Validity, Personnel Psychology, 28, 1975, 563-575.

4. Lynn Mary R., Determination and Quantification of Content Validity, Nursing Research, 35(6), 1986, 382385.

5. Zamanzadeh Vahid, Ghahramanian Akram, Rassouli Maryam, Abbaszadeh Abbas, Alavi-Majd Hamid,
Nikanfar Ali-Reza, Design and Implementation Content Validity Study: Development of an instrument for measuring Patient-Centered Communication, Journal of Caring Sciences, 4(2), 2015, 165-178.

6. Azwani Masuwai, Nor'ain Mohd Tajudin, Noor Shah Saad, Evaluating the Face and Content Validity of a Teaching and Learning Guiding Principles Instrument (TLGPI): A Perspective Study of Malaysian Teacher Educators, Malaysian Journal of Society and Space, 12(3), 2016, 11-21.

7. Cohen Jacob, A Coefficient of Agreement for Nominal Scales, Educational and Psychological Measurement, 20(1), 1960, 37-46.

8. Fleiss J. L., Measuring Nominal Scale Agreement among Many Raters, Psychological Bulletin, 76(5), 1971, 378-382.

Source of Support: None declared.

Conflict of Interest: None declared.

For any question relates to this article, please reach us at: editor@globalresearchonline.net New manuscripts for publication can be submitted at: submit@globalresearchonline.net and submit_ijpsrr@rediffmail.com 